\title{
In Vitro Antioxidant Activities of Methanolic Extracts of Caesalpinia volkensii Harms., Vernonia lasiopus O. Hoffm., and Acacia hockii De Wild
}

\author{
Beatrice Muthoni Guchu ${ }^{(D},{ }^{1}$ Alex King'ori Machocho, ${ }^{2}$ Stephen Kiruthi Mwihia, ${ }^{1}$ \\ and Mathew Piero Ngugi ${ }^{1}$ \\ ${ }^{1}$ Department of Biochemistry, Microbiology and Biotechnology, School of Pure and Applied Sciences, Kenyatta University, \\ P. O. Box 43844-00100, Nairobi, Kenya \\ ${ }^{2}$ Department of Chemistry, School of Pure and Applied Sciences, Kenyatta University, P. O. Box 43844-00100, Nairobi, Kenya
}

Correspondence should be addressed to Beatrice Muthoni Guchu; bintimuthoni@gmail.com

Received 29 January 2020; Revised 18 July 2020; Accepted 22 July 2020; Published 27 September 2020

Academic Editor: Carmen Mannucci

Copyright (c) 2020 Beatrice Muthoni Guchu et al. This is an open access article distributed under the Creative Commons Attribution License, which permits unrestricted use, distribution, and reproduction in any medium, provided the original work is properly cited.

\begin{abstract}
Oxidative stress is the result of the disparity between pro-oxidants and antioxidants in an organism, and it is important in the pathogenesis of several degenerative disorders, such as arthritis, Alzheimer's, cancer, and cardiovascular diseases. Free radicals can damage biomolecules, such as nucleic acids, lipids, proteins, polyunsaturated fatty acids, and carbohydrates, and the DNA leading to mutations. The use of antioxidants is effective in delaying the oxidation of biomolecules. Antioxidants are complexes found in the food that can retard or deter oxidation by preventing the initiation and propagation of oxidizing chain reactions. Medicinal plants have been used for centuries by man to manage diseases and have a host of antioxidant complexes. Traditionally, Caesalpinia volkensii, Vernonia lasiopus, and Acacia hockii have folkloric remedies against associated oxidative stress-mediated complications. However, the upsurge in its use has not been accompanied by scientific validations to support these claims. In this study, in vitro antioxidant activity of Caesalpinia volkensii, Vernonia lasiopus, and Acacia hockii collected from Embu County (Kenya) were determined by radical scavenging activities of 1,1-diphenyl-2-picrylhydrazyl (DPPH) and hydroxyl radical in addition to ferric reducing antioxidant power analyzed against that of L-ascorbic acid as the standard. The obtained results revealed remarkable antioxidant activities of the studied plant extracts as evidenced by the low IC50 and EC50 values. These antioxidant activities could be due to the presence of antioxidants phytochemicals such as flavonoids, phenols, terpenoids, and saponins among others. Therefore, the therapeutic potential of this plant could be due to their antioxidant properties. This study recommends bioassay of the extracts against oxidative stress-related disorders for development of phytomedicine with antioxidant properties.
\end{abstract}

\section{Introduction}

Oxidative stress is the major driving factor responsible for the initiation and progression of cancer, diabetes mellitus, cardiovascular diseases, neurodegenerative diseases, and inflammatory diseases among other syndromes [1]. The condition is brought by excessive generation of free oxygen and nitrogen species or their inefficient quenching in the cell. Free oxygen and nitrogen species are unstable molecules that are present in the environment (exogenous) and are also generated in the body (endogenous) during the normal aerobic metabolic processes in the body [2]. Exogenous sources of free radicals include cigarette smoke, exposure to ozone, ionizing radiation such as X-rays, and drugs among others. On the other hand, endogenous sources of free radicals include the electron transfer chain reactions in the mitochondria, xanthine oxidase pathway, during disease states such as inflammation, ischemia, and reperfusion injury [3].

The body possesses a complex antioxidant defense system, comprising of enzymatic and nonenzymatic 
pathways, which in the normal physiologic state, maintain a steady equilibrium between prooxidants and antioxidants, thereby ensuring well-being [1]. The enzymatic antioxidants comprise the catalase, glutathione peroxidase, and superoxide dismutase. Conversely, nonenzymatic antioxidants employed by the body include the bilirubin, uric acid, and lactoferrin among others. However, during disease states, the endogenous antioxidant systems are overwhelmed, leading to accumulation of excessive free radicals, which in turn cause oxidative stress-associated damage to cellular machinery, as implicated in various diseases [4].

Conventionally, oxidative stress is managed using various synthetic antioxidant compounds such as butylated hydroxyanisole (BHA), butylated hydroxytoluene (BHT), and propyl gallate (PG). Despite their usage, these synthetic antioxidant compounds have been associated with undesirable effects [5]. For instance, BHT and BHA cause hepatotoxicity and have been demonstrated to be carcinogenic. Additionally, synthetic antioxidants are inaccessible, unaffordable, and labile, thus limiting their utilization [3]. Therefore, due to the profound consequences of oxidative stress and the drawbacks of synthetic antioxidants, the need for alternative antioxidants, which are safer, easily accessible, and potent, are warranted [6], hence the current study.

Considering the available alternative and complementary strategies, medicinal plants stand a better chance of providing potent, safer, affordable, and easily accessible therapies for oxidative stress-related maladies [7]. Medicinal plants contain various secondary metabolites, which have demonstrated a wide spectrum of pharmacologic activities. Antioxidants properties of plants have been demonstrated to play a protective role in the body against diseases, since their consumption lowers the risk of cancer, heart disease, hypertension, dementia, and stroke [8].

The major groups of phytochemicals that contribute to antioxidant capacity of plants include polyphenols and vitamins (A, C, and E). Phenolic compounds of plants are hydroxylated derivatives of benzoic acid and cinnamic acids, which possess antioxidant and anticarcinogenic effects [3]. They include phenols, flavonoids, coumarins, tannins, and anthocyanidins. These phytoactive complexes are important in plant defense mechanisms against biotic and abiotic stresses [9]. When plants or plant products rich in these phytoactive principles are consumed, they are deemed to confer the same beneficial effects to humans [8]. For instance, flavonoids have for long been recognized to possess anti-inflammatory, antiallergic, antiviral, immunomodulatory, antiaging, and antiproliferative properties [10].

The search for better alternatives to synthetic antioxidants has triggered a significant research interest on dietary and medicinal plants that can inhibit, reverse, or ameliorate diseases caused by oxidative stress $[3,10]$. In this quest, we investigated the in vitro antioxidant activities of the methanolic extracts of Vernonia lasiopus (O. Hoffm.), Acacia hockii (De Wild.), and Caesalpinia volkensii (Harms.). Vernonia lasiopus (O. Hoffm.) is a shrub of Asteraceae family. Leaf infusion and decoctions of $V$. lasiopus are used by traditional herbalists in Kenya for the treatment and management of malaria, epilepsy, inflammation, pain, and other diseases $[11,12]$. Previous studies have implicated various plants of the Asteraceae family to have antioxidant activities. For instance, Iwalokun et al. [13] reported the antioxidant effects of an aqueous extract of Vernonia amygdalina leaves against acetaminophen-induced hepatotoxicity and oxidative stress in mice.

Acacia hockii (De Wild.) is a shrub in the Fabaceae family. The root and back decoctions of $A$. hockii are used in traditional medicine to treat inflammation and associated diseases including gout [12]. Other plants of genus Acacia, in the Fabaceae family, have been shown to have harbor antioxidant properties. An investigation of one of the Acacia species, Acacia mearnsii, has led to the isolation of a strong antioxidant molecule, with neuroprotective properties [14].

Caesalpinia volkensii (Harms.) is a shrub belonging to the Caesalpiniaceae family. Fruit and leaf preparations of this plant are used by herbalists to manage diarrhea, dysentery, ophthalmic diseases, and diabetes mellitus complications [12]. Various plants in Caesalpiniaceae family, including Bauhinia rufescens, have antioxidant properties as described by Aliyu et al. [15]. In this study, Caesalpinia volkensii, Acacia hockii, and Vernonia lasiopus were selected based on their ethnomedical usage in the management of oxidative stress-related diseases. Thus, the current study provides a framework towards the discovery of alternative, safer, affordable, and efficacious antioxidants to counter oxidative stress-related disorders.

\section{Materials and Methods}

2.1. Plant Materials and Processing. Fresh leaves of Caesalpinia volkensii and Vernonia lasiopus and stem bark of Acacia hockii were collected from their natural habitats, in Mbeere North subcounty, Embu County, where they grew naturally. The plants were chosen based on an extensive ethnomedical survey and folklore reports from the local practicing herbalists [12]. Primarily, the plants were identified by their local names, Caesalpinia volkensii ("Mubuthi"), Vernonia lasiopus ("Mucatha"), and Acacia hockii ("Mugaa"), and diseases they treat by the help of a reputable local herbalist.

The plant samples were furnished to an acknowledged taxonomist for botanical authentication. The voucher specimens were deposited in plant science department of Kenyatta University for future reference. Samples were sorted out properly and transported to the Department of Biochemistry, Microbiology and Biotechnology laboratories at Kenyatta University where they were shade dried for a period of two weeks. After drying, the plant materials were ground well using an electric plant mill into a fine powder, packaged in well-labeled airtight containers, and stored at room temperature awaiting extraction.

2.2. Preparation of Methanolic Extracts. Approximately $400 \mathrm{~g}$ of each of the powdered plant materials was soaked in a liter of analytical grade methanol in a 2-liter capacity conical flask. The flasks containing each plant material were shaken regularly, corked, and left to stand for 48 hours at room 
temperature. In each case, the menstruum was separated by filtration through Whatman filter paper No. 1. The filtrates were then concentrated using a rotary evaporator at $50^{\circ} \mathrm{C}$ and later in a hot-air oven at $35^{\circ} \mathrm{C}$ to dry completely. The concentrates were put in airtight containers and stored at $4^{\circ} \mathrm{C}$ awaiting use in in vitro bioassay [16].

2.3. Qualitative Phytochemical Screening. Qualitative tests for various phytochemicals present in the methanolic leaf extracts of Caesalpinia volkensii and Vernonia lasiopus and the methanolic stem bark extract of Acacia hockii were carried out using standard phytochemical screening procedures [16]. Visual examination of the appearance of colour or frothing was used as an indicator for the presence or absence of a given phytochemical group.

2.3.1. Test for Saponins. About $2 \mathrm{~g}$ of each of the studied plant extracts was weighed and dissolved in $5 \mathrm{ml}$ of distilled water. Thereafter, aliquots of $2 \mathrm{ml}$ were taken from each plant extract solution, stirred for 30 seconds, and briskly agitated. The setups were then allowed to settle for 15 minutes. The presence of frothing, which persists for over 15 minutes, is an indication of the presence of saponins in the tested sample [16].

2.3.2. Test for Alkaloids. About $2 \mathrm{~g}$ of each of the studied plant extracts was added to $10 \mathrm{ml}$ of $0.1 \mathrm{M}$ hydrochloric acid, warmed in a waterbath $\left(50^{\circ} \mathrm{C}\right)$ for 5 minutes, and filtered through Whatman filter paper No. 1. After cooling, 3 drops of Dragendorff's reagent were added and mixed. The appearance of a reddish-brown colour is a positive indication for the presence of alkaloids in the sample [16].

2.3.3. Test for Terpenoids. Into clean test tubes, $2 \mathrm{ml}$ of alcoholic extracts were mixed with 5 drops of acetic anhydride. Thereafter, 5 drops of concentrated sulphuric were carefully added through the side of the test tube.

The formation of a blue ring at the interface shows the presence of terpenoids in the tested sample [16].

2.3.4. Test for Flavonoids. To $2 \mathrm{ml}$ of alcoholic extracts of the studied plants and 5 drops of concentrated hydrochloric acid were added. The formation of a red colour indicates the presence of flavonoids. To another portion of the alcoholic extracts $(2 \mathrm{ml}), 1 \mathrm{ml}$ of dilute ammonia was added and gently mixed. A greenish-yellow colour indicates the presence of flavonoids [16].

2.3.5. Test for Cardiac Glycosides. To test for cardiac glycosides presence, $0.5 \mathrm{~g}$ of the extract was dissolved in $2 \mathrm{ml}$ glacial acetic acid containing 2 drops of $10 \%$ ferric chloride solution. One milliliter of concentrated $\mathrm{H}_{2} \mathrm{SO}_{4}$ was then slowly introduced into the underlying mixture. Appearance of either a violet band at the boundary is a positive test for the deoxy sugars (cardenolides) [16].
2.3.6. Test for Steroids. The presence of steroids in the studied plant extracts was determined in this study. About $0.5 \mathrm{~g}$ of each extract was dissolved in $2 \mathrm{ml}$ of chloroform. This was followed by addition of 3 drops of the Liebermann-Burchard reagent and gently agitated. The presence of reddish-purple colour indicates the presence of steroids [16].

2.3.7. Test for Phenols. About $0.5 \mathrm{~g}$ of each of the studied plant extracts was boiled in $5 \mathrm{ml}$ of $70 \%$ ethanol in a waterbath for 5 minutes and then filtered through Whatman filter paper No. 1. After cooling, 5 drops of $5 \%$ ferric chloride were added and mixed. The appearance of a green precipitate indicates the presence of phenols in the sample [16].

\subsection{Determination of In Vitro Antioxidant Activities of the Studied Plant Extracts}

2.4.1. Ferric Reducing Antioxidant Power Assay. The reducing power of the extracts was determined according to the method described by Oyaizu [17], with some modifications. Briefly, five different concentrations of methanolic extracts $(0.2,0.4,0.6,0.8$, and $1 \mathrm{mg} / \mathrm{ml})$ and L-ascorbic acid at same concentrations were mixed with $2 \mathrm{ml}$ phosphate buffer $(0.2 \mathrm{M}, \mathrm{pH} 6.6)$ and $2 \mathrm{ml}$ of $1 \%$ potassium ferricyanide $\left(\mathrm{K}_{3} \mathrm{Fe}(\mathrm{CN})_{6}\right)$. The mixture was incubated at $50^{\circ} \mathrm{C}$ for 20 minutes. Then, $2 \mathrm{ml}$ of $10 \%$ trichloroacetic acid (TCA) was added, and the mixture was centrifuged at 1000 revolutions per minute $(\mathrm{rpm})$ for $10 \mathrm{~min}$. The supernatant $(2 \mathrm{ml})$ was aspirated and mixed with $2 \mathrm{ml}$ of distilled water and $1 \mathrm{ml}$ of $0.1 \%$ ferric chloride $\left(\mathrm{FeCl}_{3}\right)$. In each case, the experiment was performed in triplicate. Afterward, the absorbances were measured spectrophotometrically at $700 \mathrm{~nm}$ using a UV-vis spectrophotometer and recorded. The concentrations of each extract able to yield an absorbance value of 0.5 were determined from the graph of absorbance at $700 \mathrm{~nm}$ against extract concentrations and considered as the median effective concentration (EC50).

2.4.2. Determination of 1,1 , dipheny-2-picrylhydrazyl (DPPH) Radical Scavenging Activities. The DPPH radical scavenging assay was performed using 1,1 diphenyl-2-picrylhydrazyl (DPPH) according to the method described by Brand-Williams et al. [18] with some modifications. Briefly, five different concentrations of the studied plant extracts $(0.0625,0.125,0.25,0.5$, and $1 \mathrm{mg} / \mathrm{ml})$ were prepared in methanol (analytical grade). The same concentrations were also prepared for L-ascorbic acid, which was used as a standard antioxidant. $1 \mathrm{ml}$ of each studied extract was transferred into a clean test tube into which $0.5 \mathrm{ml}$ of $0.3 \mathrm{mM}$ DPPH in methanol was added. The mixture was shaken and left to stand in the dark at room temperature for 15 minutes. Blank solutions comprising of the studied extract solutions $(2.5 \mathrm{ml})$ and $1 \mathrm{ml}$ of methanol were used as baseline.

The negative control comprised $2.5 \mathrm{ml}$ of DPPH solution and $1 \mathrm{ml}$ of methanol, while L-ascorbic acid at the same concentrations as the studied extracts was used as the 
positive control. After incubation in the dark, the absorbance values were measured at $517 \mathrm{~nm}$ using a spectrophotometer. The experiments were performed in triplicate. The DPPH radical scavenging activity was estimated using the equation described by Brand-Williams et al. [18].

$$
\% \text { Radical scavenging activity }=\frac{A_{\mathrm{c}}-A_{\mathrm{s}}}{A_{\mathrm{c}}} \times 100,
$$

where $A_{\mathrm{s}}$ is the absorbance of the sample, and $A_{\mathrm{c}}$ is the absorbance of the control.

The half maximal inhibitory concentration (IC50) of the extracts was computed from a plot of percentage DPPH free radical inhibition versus the extract concentration.

2.4.3. Hydroxyl Radical Scavenging Activities. The hydroxyl radical scavenging activity was performed as per the method described by Klein et al. [19] with minor modifications. The reaction mixture was constituted by adding $2.4 \mathrm{ml}$ of phosphate buffer $(\mathrm{pH} \mathrm{7.8)}$ into test tubes. To the same test tubes, $90 \mu \mathrm{l}$ of $1 \mathrm{mM} \mathrm{1,} 10$ phenanthroline, $150 \mu \mathrm{l}$ of $0.1 \mathrm{mM}$ hydrogen peroxide, $60 \mu \mathrm{l}$ of $1 \mathrm{mM}$ iron (III) chloride, and
TABLE 1: Qualitative phytochemical composition of methanolic leaf extracts of $C$. volkensii and $V$. lasiopus and stem bark extracts A. hockii.

\begin{tabular}{lccc}
\hline Phytochemicals & C. volkensii & V. lasiopus & Acacia hockii \\
\hline Flavonoids & + & + & + \\
Phenols & + & + & + \\
Steroids & - & - & + \\
Saponins & + & + & + \\
Alkaloids & + & + & + \\
Cardiac glycosides & - & - & + \\
Terpenoids & + & + & + \\
\hline
\end{tabular}

+, present; -, absent

$1.5 \mathrm{ml}$ of the Phytexponent and the standard (L-ascorbic acid) at different concentrations $(100 \%, 10 \%, 1 \%, 0.1 \%$, and $0.01 \%)$ were added except in the controls, followed by incubation at room temperature for 5 minutes. The increase in absorbance at $560 \mathrm{~nm}$ was measured, and radical scavenging activity was calculated using the following formula:

$$
\% \text { Radical scavenging activity }=\left[\frac{\text { Abs of control }- \text { Abs of sample }}{\text { Abs of control }}\right] \times 100
$$

2.5. Determination of Total Phenolic Contents. The total phenolic content of the extracts was measured according to the Folin-Ciocalteu method adapted from Do et al. [20], with some modifications. Briefly, the extract $(1 \mathrm{ml})$ was mixed with $2 \mathrm{ml}$ of Folin-Ciocalteu reagent, which was prepared by dilution with distilled water in a ratio of $1: 10 \mathrm{v} / \mathrm{v}$, after which $1 \mathrm{ml}$ of $20 \%$ sodium carbonate $\left(\mathrm{Na}_{2} \mathrm{CO}_{3}\right)$ was added. The mixture was shaken for 20 seconds and incubated at $40^{\circ} \mathrm{C}$ for 30 minutes. Absorbance was measured at $765 \mathrm{~nm}$. Gallic acid was used for the generation of the standard curve. The total phenolic content was expressed as mg of gallic acid equivalents (GAE) per gram (g) of the studied extracts. The experiment was repeated in triplicates.

2.6. Determination of Total Flavonoid Contents. The total flavonoid content of the extracts was evaluated through a technique described by Park et al. [21]. In a $10 \mathrm{ml}$ test tube, $0.3 \mathrm{ml}$ of extracts, $3.4 \mathrm{ml}$ of $30 \%$ methanol, $0.15 \mathrm{ml}$ of $\mathrm{NaNO}_{2}$ $(0.5 \mathrm{M})$, and $0.15 \mathrm{ml}$ of $\mathrm{AlCl}_{3} \cdot 6 \mathrm{H}_{2} \mathrm{O}(0.3 \mathrm{M})$ were mixed. After 5 minutes, $1 \mathrm{ml}$ of $\mathrm{NaOH}(1 \mathrm{M})$ was added and mixed well, and the absorbance was measured against the reagent blank at $510 \mathrm{~nm}$. The standard curve for total flavonoids prepared using quercetin standard solution $(0-100 \mathrm{mg} / \mathrm{l})$. The total flavonoids were expressed as milligrams of quercetin equivalents per $g$ of sample. The experiment was repeated thrice.
2.7. Data Management and Statistical Analysis. Quantitative data were presented in tables, and the data were then exported into Minitab statistical software version 17.0 for analysis. The data were subjected to descriptive statistics and stated as mean \pm standard error of the mean (SEM). Oneway analysis of variance (ANOVA) was used to analyze whether there was any significant difference among the means of different groups. This was followed by Tukey's tests for pairwise comparisons and separation of means. $P<0.05$ was considered statistically significant. On the other hand, qualitative data on phytochemical analysis was only tabulated.

\section{Results}

3.1. Qualitative Phytochemical Screening. Qualitative phytochemical testing of the studied plant extracts showed the presence of saponins, terpenoids, flavonoids, alkaloids, and phenols. However, C. volkensii and V. lasiopus lacked cardiac glycosides and steroids (Table 1).

\subsection{Antioxidant Activity}

3.2.1. Ferric Reducing Antioxidant Power (FRAP). Generally, the methanolic extracts of three studied medicinal plants exhibited remarkable concentration-dependent increases in absorbance values at a wavelength of $700 \mathrm{~nm}$ (Table 2). At all the tested concentrations, the extracts of A. hockii had significantly higher absorbance values than those recorded for $C$. volkensii and $V$. lasiopus extracts 
TABle 2: In vitro ferric reducing antioxidant power activities of methanolic extracts of C. volkensii, V. lasiopus, and A. hockii.

\begin{tabular}{|c|c|c|c|c|}
\hline \multicolumn{5}{|c|}{ Absorbance at $700 \mathrm{~nm}$} \\
\hline Concentration in $(\mathrm{mg} / \mathrm{ml})$ & L-ascorbic acid & A. hockii & V. lasiopus & C. volkensii \\
\hline 0.2 & $1.72 \pm 0.01 \mathrm{e}^{\mathrm{A}}$ & $1.63 \pm 0.02_{\mathrm{d}}{ }^{\mathrm{B}}$ & $1.35 \pm 0.01_{\mathrm{e}}{ }^{\mathrm{C}}$ & $1.05 \pm 0.02 \mathrm{e}^{\mathrm{D}}$ \\
\hline 0.4 & $1.92 \pm 0.00_{\mathrm{d}}^{\mathrm{A}}$ & $1.82 \pm 0.00_{c}{ }^{B}$ & $1.47 \pm 0.01_{\mathrm{d}}{ }^{\mathrm{C}}$ & $1.23 \pm 0.01_{\mathrm{d}} \mathrm{D}$ \\
\hline 0.6 & $2.25 \pm 0.01_{\mathrm{c}}^{\mathrm{A}}$ & $1.88 \pm 0.01_{c}{ }^{B}$ & $1.72 \pm 0.01_{\mathrm{C}}{ }^{\mathrm{C}}$ & $1.42 \pm 0.02_{c}{ }^{D}$ \\
\hline 0.8 & $2.56 \pm 0.02_{\mathrm{b}}^{\mathrm{A}}$ & $2.18 \pm 0.02_{\mathrm{b}}{ }^{\mathrm{B}}$ & $1.87 \pm 0.02_{\mathrm{b}}^{\mathrm{C}}$ & $1.65 \pm 0.01_{b}{ }^{D}$ \\
\hline 1 & $2.75 \pm 0.00_{\mathrm{a}}^{\mathrm{A}}$ & $2.54 \pm 0.04_{\mathrm{a}}^{\mathrm{B}}$ & $1.93 \pm 0.02_{\mathrm{a}}{ }^{\mathrm{C}}$ & $1.81 \pm 0.01_{\mathrm{a}}{ }^{\mathrm{D}}$ \\
\hline $\mathrm{EC}_{50}(\mathrm{mg} / \mathrm{ml})$ & 0.14 & 0.16 & 0.17 & 0.21 \\
\hline
\end{tabular}

The values are expressed as mean \pm SEM. Values with the same uppercase superscript letter within the same row and those with the same lowercase subscript letter within the same column are not significantly different $(P>0.05$, one-way ANOVA followed by Tukey's test).

$(P<0.05$; Table 2). Notably, at all the tested concentrations, the methanolic extract of $V$. lasiopus produced significantly higher absorbance values compared with the absorbance generated by $C$. volkensii extracts $(P<0.05$; Table 2$)$. However, the standard (L-ascorbic acid) demonstrated significantly higher absorbances than those obtained for the three studied plant extracts $(P<0.05$; Table 2$)$. Furthermore, the half effective concentrations (EC50) of the studied plant extracts required to produce an absorbance value of 0.5 were determined in this study. It was demonstrated that the EC50 value for L-ascorbic acid was lower than the EC50 values of all the studied plant extracts. However, the methanolic extract of $A$. hockii had the lowest EC50 value compared with the EC50 values of C. volkensii and V. lasiopus (Table 2). Furthermore, it was observed that methanolic extracts of $V$. lasiopus had lower EC50 values than C. Volkensii (Table 2).

3.2.2. DPPH Radical Scavenging Activities of Methanolic Extracts of $C$. volkensii, $V$. lasiopus, and $A$. hockii. The methanolic extracts of $C$. volkensii, $V$. lasiopus, and A. hockii also demonstrated remarkable in vitro DPPH radical scavenging activities in a dose-dependent trend (Table 3 ). The standard (L-ascorbic acid) exhibited significantly higher $\mathrm{DPPH}$ radical scavenging activities than the $\mathrm{DPPH}$ radical scavenging activities of all the studied methanolic plant extracts $(P<0.05$; Table 3$)$. At all the studied concentrations, the methanolic extract of $A$. hockii produced significantly higher DPPH radical scavenging activities than those recorded for the methanolic extracts of $C$. volkensii and $V$. lasiopus $(P<0.05$; Table 3$)$. The percentage $\mathrm{DPPH}$ radical scavenging activities of the methanolic extracts of $V$. lasiopus and $A$. hockii at a concentration of $0.5 \mathrm{mg} / \mathrm{ml}$ were not significantly different $(P>0.05)$; however, the observed percentage radical scavenging activities were significantly higher than that of $C$. volkensii $(P<0.05$; Table 3$)$.

The concentrations of the studied plant extracts required to scavenge $50 \%$ of the $\mathrm{DPPH}$ radicals $\left(\mathrm{IC}_{50}\right)$ were also determined in this study. The IC50 values for the C. volkensii, $V$. lasiopus, and $A$. hockii extracts were $0.25 \mathrm{mg} /$ $\mathrm{ml}, 0.24 \mathrm{mg} / \mathrm{ml}$, and $0.12 \mathrm{mg} / \mathrm{ml}$, respectively. On the other hand, the IC50 value of the standard (L-ascorbic acid) was $0.06 \mathrm{mg} / \mathrm{ml}$.
3.2.3. In Vitro Hydroxyl Radical Scavenging Activities of Methanolic Extracts of C. volkensii, V. lasiopus, and A. hockii. The methanolic extracts of $C$. volkensii, V. lasiopus, and A. hockii exhibited remarkable in vitro hydroxyl radical scavenging activities (Table 4). At all the tested concentrations, the methanolic extracts of $A$. hockii demonstrated significantly higher hydroxyl radical scavenging activities than those of the methanolic extracts of $C$. volkensii and $V$. lasiopus extracts $(P<0.05$; Table 4$)$. Moreover, at all tested concentrations, the methanolic extracts of $V$. lasiopus demonstrated significantly higher hydroxyl radical scavenging activities compared to the hydroxyl radical scavenging activities of the methanolic extracts of $C$. volkensii. However, at all the tested concentrations, the in vitro hydroxyl radical scavenging activities of L-ascorbic acid were significantly higher than those of the methanolic extracts of C. volkensii, V. lasiopus, and A. hockii $(P<0.05$; Table 4$)$.

In this study, the concentration of the studied plant extracts capable of scavenging $50 \%$ of the hydroxyl radicals $\left(\mathrm{IC}_{50}\right)$ was also determined. The results showed that the IC50 values for the methanolic extracts of $C$. volkensii, V. lasiopus, and $A$. hockii extracts were $0.11 \mathrm{mg} / \mathrm{ml}, 0.23 \mathrm{mg} / \mathrm{ml}$, and $0.49 \mathrm{mg} / \mathrm{ml}$, respectively. Besides, the IC50 value of the standard (L-ascorbic acid) was $1.05 \mathrm{mg} / \mathrm{ml}$ (Table 4).

\subsection{Total Phenolic and Flavonoid Contents of Methanolic} Extracts of $C$. volkensii, $V$. lasiopus, and A. hockii. Determination of the quantity of total phenols of methanolic extracts of C. volkensii, $V$. lasiopus, and A. hockii was performed in this study. The results showed that the methanolic extract of $A$. hockii had a significantly higher total phenolic content $(41.78 \pm 0.93 \mathrm{mg}$ of $\mathrm{GAE} / \mathrm{g})$ than the phenolic content in the methanolic extracts of $V$. lasiopus $(6.04 \pm 0.032 \mathrm{mg}$ of $\mathrm{GAE} / \mathrm{g})$ and $C$. volkensii $(28.51 \pm 0.061 \mathrm{mg}$ of $\mathrm{GAE} / \mathrm{g})(P<0.05$; Table 5$)$.

On the other hand, analysis of the total flavonoid content, in methanolic extracts of the studied plant extracts, showed that $A$. hockii contained significantly higher total flavonoids $(39.89 \pm 0.04 \mathrm{mg}$ of $\mathrm{QE} / \mathrm{g}$ ) compared with the total flavonoid content in the methanolic extracts of $V$. lasiopus $(32.89 \pm 0.01 \mathrm{mg}$ of $\mathrm{QE} / \mathrm{g})$ and $C$. volkensii $(22.52 \pm 0.09 \mathrm{mg}$ of $\mathrm{QE} / \mathrm{g})(P<0.05$; Table 6$)$. 
TAвLE 3: In vitro DPPH scavenging activities of methanolic extracts of C. volkensii, V. lasiopus, and A. hockii.

\begin{tabular}{|c|c|c|c|c|}
\hline \multicolumn{5}{|c|}{ DPPH scavenging activity (\% inhibition) } \\
\hline \multirow[t]{2}{*}{ Concentration in $\mathrm{mg} / \mathrm{ml}$} & \multicolumn{4}{|c|}{ Treatments } \\
\hline & L-ascorbic acid & C. volkensii & V. lasiopus & A. hockii \\
\hline 0.0625 & $46.81 \pm 0.46_{\mathrm{e}}^{\mathrm{A}}$ & $33.16 \pm 0.60_{\mathrm{e}}{ }^{\mathrm{D}}$ & $36.44 \pm 0.75_{\mathrm{e}}{ }^{\mathrm{C}}$ & $39.38 \pm 0.30_{c}{ }^{B}$ \\
\hline 0.125 & $62.18 \pm 0.18_{\mathrm{d}}^{\mathrm{A}}$ & $36.10 \pm 0.75_{\mathrm{d}}{ }^{\mathrm{D}}$ & $44.73 \pm 1.73_{\mathrm{d}}{ }^{\mathrm{C}}$ & $53.37 \pm 1.30_{\mathrm{bc}}{ }^{\mathrm{B}}$ \\
\hline 0.25 & $73.06 \pm 1.03_{\mathrm{c}}^{\mathrm{A}}$ & $51.64 \pm 0.46_{c}{ }^{C}$ & $50.60 \pm 0.17_{c}^{D}$ & $66.67 \pm 1.05_{\mathrm{ab}} \mathrm{B}$ \\
\hline 0.5 & $81.35 \pm 0.30_{\mathrm{b}}^{\mathrm{A}}$ & $61.31 \pm 0.75_{\mathrm{b}} \mathrm{C}$ & $70.47 \pm 1.79_{\mathrm{b}}^{\mathrm{B}}$ & $70.47 \pm 1.79_{b}{ }^{B}$ \\
\hline 1 & $87.22 \pm 0.75_{\mathrm{a}}^{\mathrm{A}}$ & $67.36 \pm 0.30_{a}{ }^{\mathrm{D}}$ & $76.86 \pm 0.96_{\mathrm{a}}{ }^{\mathrm{C}}$ & $82.73 \pm 0.62{ }^{\mathrm{B}}$ \\
\hline $\mathrm{IC}_{50}$ & 0.06 & 0.25 & 0.24 & 0.12 \\
\hline
\end{tabular}

The values are expressed as mean \pm SEM. Values with the same uppercase superscript letter within the same row and those with the same lowercase subscript letter within the same column are not significantly different $(P>0.05$, one-way ANOVA followed by Tukey's test).

TABLE 4: In vitro hydroxyl radical scavenging activities of methanolic extracts of C. volkensii, V. lasiopus, and A. hockii.

\begin{tabular}{|c|c|c|c|c|}
\hline \multicolumn{5}{|c|}{ Hydroxyl radical scavenging activity (\% inhibition) } \\
\hline Concentration in $\mathrm{mg} / \mathrm{ml}$ & L-ascorbic acid & C. volkensii & V. lasiopus & A. hockii \\
\hline 0.0625 & $87.50 \pm 1.30_{\mathrm{a}}^{\mathrm{A}}$ & $66.99 \pm 0.32_{\mathrm{a}}^{\mathrm{D}}$ & $73.93 \pm 0.91_{\mathrm{a}}^{\mathrm{C}}$ & $81.52 \pm 0.28_{a^{B}}$ \\
\hline 0.125 & $80.56 \pm 0.65_{b}{ }^{\mathrm{A}}$ & $56.41 \pm 0.37_{\mathrm{b}}{ }^{\mathrm{D}}$ & $61.75 \pm 0.83_{\mathrm{b}}{ }^{\mathrm{C}}$ & $73.56 \pm 0.28_{b}{ }_{b}^{B}$ \\
\hline 0.25 & $73.29 \pm 2.03_{\mathrm{c}}^{\mathrm{A}}$ & $46.69 \pm 0.36_{c}^{\mathrm{D}}$ & $53.74 \pm 0.65_{\mathrm{c}}^{\mathrm{C}}$ & $63.14 \pm 0.56_{c}^{B}$ \\
\hline 0.5 & $62.39 \pm 0.39_{\mathrm{d}}^{\mathrm{A}}$ & $40.71 \pm 0.56_{\mathrm{d}}^{\mathrm{D}}$ & $47.22 \pm 0.21_{\mathrm{d}}^{\mathrm{C}}$ & $50.86 \pm 0.39_{d^{B}}$ \\
\hline 1 & $50.64 \pm 0.68 \mathrm{e}^{\mathrm{A}}$ & $30.98 \pm 0.28_{\mathrm{e}}^{\mathrm{D}}$ & $38.46 \pm 0.56_{e}{ }^{C}$ & $43.38 \pm 0.28 \mathrm{e}^{\mathrm{B}}$ \\
\hline $\mathrm{IC}_{50}$ & 1.05 & 0.11 & 0.23 & 0.49 \\
\hline
\end{tabular}

The values are expressed as mean \pm SEM. Values with the same uppercase superscript letter within the same row and those with the same lowercase subscript letter within the same column are not significantly different $(P>0.05$, one-way ANOVA followed by Tukey's test).

TABle 5: Total phenolic contents of methanolic extracts of C. volkensii, V. lasiopus, and A. hockii.

\begin{tabular}{lc}
\hline Sample & TPC $(\mathrm{mgGAE} / \mathrm{g})$ \\
\hline Acacia hockii & $41.78 \pm 0.09^{\mathrm{a}}$ \\
Vernonia lasiopus & $36.04 \pm 0.03^{\mathrm{b}}$ \\
Caesalpinia volkensii & $28.51 \pm 0.06^{\mathrm{c}}$ \\
\hline
\end{tabular}

TPC, total phenolic content; mgGAE/g, milligrams gallic acid equivalent per gram of sample. Values are expressed as mean \pm SEM. Means with different superscript letters are significantly different by one way ANOVA followed by Tukey's test.

TABLE 6: Total flavonoid contents in the methanolic extracts of $C$. volkensii, V. lasiopus, and A. hockii.

\begin{tabular}{lc}
\hline Sample & TFC $(\mathrm{mg} \mathrm{QE} / \mathrm{g})$ \\
\hline Acacia hockii & $39.89 \pm 0.04^{\mathrm{a}}$ \\
Vernonia lasiopus & $32.89 \pm 0.01^{\mathrm{b}}$ \\
Caesalpinia volkensii & $22.52 \pm 0.09^{\mathrm{c}}$ \\
\hline
\end{tabular}

TFC, total flavonoid content; $\mathrm{mg} \mathrm{QE} / \mathrm{g}$, milligrams of quercetin equivalent per gram of sample. Values are expressed as mean \pm SEM. Means with different superscript letters are significantly different by one way ANOVA followed by Tukey's test.

\section{Discussion}

Increased production of reactive oxygen/nitrogen species and decreased capacity of antioxidant defenses in the body leads to oxidative stress $[22,23]$. Generation of reactive oxygen/nitrogen species (ROS/RNS) is inevitable for aerobic organisms and in healthy cells, and it occurs at a controlled rate [24].
Under conditions of oxidative stress, ROS/RNS production is dramatically increased, resulting in subsequent alteration of membrane lipids, proteins, and nucleic acids [6]. Oxidative damage of these biomolecules is associated with aging and a variety of pathological events, including atherosclerosis, carcinogenesis, ischemia reperfusion injury, and neurodegenerative disorders [25].

To maintain homeostasis in the redox system and protect the body against ROS and RNS, humans have evolved complex antioxidant systems, which work to avert deleterious effects of oxidative stress [26]. The body's antioxidant defense systems are of endogenous and exogenous origin [27]. Exogenous sources of antioxidants include $\beta$-carotene, L-ascorbic acid (vitamin C), $\alpha$-tocopherol, and tocotrienols (vitamin E), which are derived from dietary foods we consume [28]. Endogenous sources of antioxidant defenses include superoxide dismutase (SOD), glutathione peroxidase (GPx), glutathione reductase, and catalase (CAT) enzymes, which catalyze free radical quenching reactions [28-30].

Synthetic antioxidants such as propyl gallate (PG), butylated hydroxyanisole (BHA), and butylated hydroxytoluene (BHT), currently used against oxidative stress, have been associated with adverse health effects including hepatic damages and malignancies. Additionally, they have limited potency in animal models and humans [31]. Currently, there is an upsurge of interest to substitute synthetic antioxidants with naturally occurring antioxidants from plants since they are considerably safer, easily accessible, and affordable $[32,33]$. The objective of the current study was to assay for the presence of phytochemicals and the in vitro antioxidant 
activities of methanolic stem bark extracts of $A$. hockii and leaf extracts of $V$. lasiopus and $C$. volkensii.

Research has indicated that antioxidant activities ought not to be established based on a single antioxidant experimental model [6]. In practice, several in vitro examination techniques are taken into consideration for assessing antioxidant activities $[6,34]$. Some of the in vitro antioxidant tests used include hydroxyl scavenging activity, lipid peroxidation inhibition capacity (LPIC), the oxygen radical absorbance capacity (ORAC) method, the nitric oxide scavenging assay, ferric reducing antioxidant power (FRAP), and DPPH scavenging effects [34].

In the present study, the ferric reducing antioxidant power (FRAP) assay was adopted [17]. This method is based on the ability of the analyte to reduce the ferric ion $\left(\mathrm{Fe}^{3+}\right)$ to ferrous ion $\left(\mathrm{Fe}^{2+}\right)[35,36]$. Hence, the $\mathrm{Fe}^{2+}$ formation can be examined by absorbance capacity at $700 \mathrm{~nm}$ [36]. Increases in absorbance at this wavelength indicate an increase in reducing power [36].

The findings of this study demonstrated a concentrationdependent increase in absorbance values of the methanolic extracts of C. volkensii, V. lasiopus, and A. hockii depicting appreciable ferric reducing antioxidant power. The findings were comparable with the in vitro study by Aliyu et al. [15] who demonstrated the antioxidant capacity of the leaves extracts of Bauhinia rufescens Lam. Additionally, a study conducted by Adesanoye and Farombi [37] established dosedependent ferric reducing activity of the methanolic leaf extracts of Vernonia amygdalina, in concurrence with our study. Furthermore, our results corroborate with those of Sowndhararajan et al. [38] who demonstrated the antioxidant potential of Indian Acacia species methanolic bark extracts.

Moreover, antioxidant activities of the studied plant extracts were appraised according to the criterion of Do et al. [20]. Based on this criterion, all the studied plant extracts were considered as very strong antioxidants since their EC50 values were all below $50 \mu \mathrm{g} / \mathrm{ml}$. The results that were observed in the study corroborated those of Fidrianny et al. [22] who demonstrated similar effects in Momordica charantia.

On the other hand, the DPPH radical scavenging technique described by Brand-Williams et al. [18] has been used across time to evaluate the antioxidant efficacy of various analytes. In this technique, molecules are considered to be antioxidants if they can scavenge for and reduce DPPH free radicals in vitro. The DPPH radical scavenging activity is observed by a characteristic change in colour from blue to yellow, which is quantified at $517 \mathrm{~nm}$ [18].

In the current study, we found that DPPH scavenging capacity of the methanolic extracts of C. volkensii, $V$. lasiopus, and A. hockii exhibited a concentration-dependent relationship as previously demonstrated by Patil et al. [39] and Vivek et al. [40] in extracts of Ageratum conyzoides and Caesalpinia pulcherrima, respectively. Moreover, metabolomic profiling of different parts (leaves, flowers, and pods) of Acacia species (Acacia nilotica, Acacia seyal, and Acacia laeta) by Abdel-Farid et al. [41] displayed that the antioxidant activities were comparable with those of the studied plant extracts.
Upon grading of the DPPH free radical scavenging effects as per the criterion of Fidrianny et al. [22], all the studied plant extracts were strong antioxidants since their $\mathrm{IC}_{50}$ values were lower than $50 \mathrm{mg} / \mathrm{ml}$.

Moreover, the ability of the studied plant extracts to scavenge for the hydroxyl radical was investigated in this study. Research has shown that the hydroxyl radicals directly denature body enzymes via oxidation of thiol (-SH) groups [42]. The hydroxyl radicals are generated through the Fenton reaction: $\mathrm{Fe}^{2+}+\mathrm{H}_{2} \mathrm{O}_{2} \longrightarrow \mathrm{Fe}^{3+}+\mathrm{OH}^{-}+\mathrm{OH}^{\bullet}$ [43]. A sample capable of scavenging for hydroxyl radicals in vitro is considered to be a potent antioxidant with potential effects in vivo.

In this study, the studied plant extracts revealed a concentration-dependent decrease in hydrogen peroxide scavenging activity in agreement with the findings reported on both acetone and aqueous whole plant extracts of Bulbine abyssinica [44]. Conversely, some studies have reported a concentration-dependent increase in hydroxyl radical scavenging activities [45]. The concentration-dependent decrease in hydroxyl radical scavenging activity could have been brought about by saturation of reactive centers of hydroxyl radicals by the high extract concentrations leading to low activities, compared to dilute concentrations that ensured easier and rapid reaction, leading to high activity. The half maximal (IC50) values for A. hockii, C. volkensii, and $V$. lasiopus were lower than $50 \mathrm{mg} / \mathrm{ml}$, which, according to Fidrianny et al. [22], rendered them very strong.

Extensive research has shown that medicinal plants contain active principles, which are responsible for antioxidant activity [46]. Various phytochemicals of antioxidant value present in medicinal plants are responsible for this bioactivity. Qualitative phytochemical profiling of the studied plant extracts showed the presence of flavonoids, phenols, and tannins among other antioxidant phytochemicals. Quantitative analysis of flavonoids and phenols, the most prominent antioxidant phytochemicals, revealed appreciable amounts, which may have contributed to the antioxidant potency of the studied plant extracts [46].

The antioxidant potential of these phytochemicals is thought to be through the reductive and oxidative capacities that allow absorption and counteracting effects of free radicals [47]. Many of these secondary metabolites are endowed with significant reductive abilities that are attributed to lesser incidences of death and suffering due to oxidative stress-related disorders [48]. Our study highly suggests that phenolics are significant components of these plants, and this is attributed to their biological effects.

Flavonoids are one of the phenolics compounds found in plants, and they are associated with various pharmacological activities including anti-inflammatory and antitumor properties, and they are capable of acting as antioxidants that shield the cells from destructive effects of free radicals $[46,48]$. The flavonoids structure, its hydroxyl atom location, and its other properties are important for antioxidant and reactive species neutralizing capacity [49]. These molecules demonstrate potent scavenging effects of destructive radicals that are associated with several disorders [50]. 
The studied medicinal plants are traditionally used to manage various diseases, which are associated with oxidative stress $[8,11,12,14]$. Based on the remarkable antioxidant effects demonstrated by the studied plant extracts in the experimented models, the medicinal value of these plants could be exerted through the remediation of oxidative stress. Thus, preliminary investigation of antioxidant activities of methanolic leaf extracts of $C$. volkensii and $V$. lasiopus and stem bark extracts of $A$. hockii we report herein provides a valuable source of biologically active elements and will consequently lead to discovery and development of potent, efficacious, safe, and affordable antioxidants to curb oxidative stress. Furthermore, our study confirms the use C. volkensii, $V$. lasiopus, and A. hockii in the management of oxidative stress-related disorders in the traditional medicine $[11,12,14]$.

\section{Conclusions and Recommendations}

From the obtained results, it was concluded that the methanolic leaf extracts of Caesalpinia volkensii and Vernonia lasiopus and the methanolic stem bark extract of Acacia hockii have appreciable antioxidant capacity and antioxidant-associated phytochemicals. Further studies that aimed at isolating and characterizing the pure phytoactive principles for enhancement are recommended. Toxicity studies on the methanolic stem bark extracts of Caesalpinia volkensii, Vernonia lasiopus, and Acacia hockii should be performed to determine their safety.

\section{Data Availability}

The data used to support this study are included within this article.

\section{Conflicts of Interest}

The authors declare no potential conflicts of interest with respect to the research, authorship, and/or publication of this article.

\section{Authors' Contributions}

Beatrice Guchu conducted the study under supervision of Mathew Ngugi and Alex Machocho. Stephen Mwihia assisted in manuscript development and review. All authors read and approved the final draft of the manuscript prior to submission.

\section{Acknowledgments}

The authors wish to acknowledge the Department of Biochemistry, Microbiology and Biotechnology of Kenyatta University for allowing them to use the departmental laboratories to perform the efficacy studies. They also acknowledge Mr. Gervason Moriasi of the Department of Biochemistry, Mt. Kenya University, and Mr. Ibrahim Waweru and Mr. Daniel Gitonga Mwaniki of the Department of Biochemistry, Microbiology and Biotechnology of Kenyatta University for technical support. The authors received no financial support for the research, authorship, and/or publication of this article. This study was supported by the Department of Biochemistry, Microbiology and Biotechnology of Kenyatta University.

\section{References}

[1] W. Arika, C. M. Kibiti, J. M. Njagi, and M. P. Ngugi, "In vitro antioxidant properties of dichloromethanolic leaf extract of Gnidia glauca (Fresen) as a promising antiobesity drug," Journal of Evidence-Based Integrative Medicine, vol. 24, 2019.

[2] A. H. Bhat, K. B. Dar, S. Anees et al., "Oxidative stress, mitochondrial dysfunction and neurodegenerative diseases; a mechanistic insight," Biomedicine \& Pharmacotherapy, vol. 74, pp. 101-110, 2015.

[3] G. A. Moriasi, A. M. Ireri, and M. P. Ngugi, "In vivo cognitiveenhancing, ex vivo malondialdehyde-lowering activities and phytochemical profiles of aqueous and methanolic stem bark extracts of Piliostigma thonningii (schum.)," International Journal of Alzheimer's Disease, vol. 2020, Article ID 1367075, 15 pages, 2020.

[4] S. Vertuani, A. Angusti, and S. Manfredini, "The antioxidants and pro-antioxidants network: an overview," Current Pharmaceutical Design, vol. 10, no. 14, pp. 1677-1694, 2004.

[5] A. Ndhlala, M. Moyo, and J. Van Staden, "Natural antioxidants: fascinating or mythical biomolecules?" Molecules, vol. 15, no. 10, pp. 6905-6930, 2010.

[6] S. K. Mwihia, "In vitro antibacterial and antioxidant activities of methanolic and dichloromethanolic seed extracts of Kenyan Annona squamosa Linn," Doctoral dissertation, Kenyatta University, Nairobi, Kenya, 2017.

[7] M. R. Goyal and H. A. R. Suleria, Eds., Human Health Benefits of Plant Bioactive Compounds: Potentials and Prospects, CRC Press, Boca Raton, FL, USA, 2019.

[8] C. Ojiewo, A. Tenkouano, J. D. A. Hughes, and J. D. H. Keatinge, "Diversifying diets: using indigenous vegetables to improve profitability, nutrition and health in Africa," Diversifying Food and Diets: Using Agricultural Biodiversity to Improve Nutrition and Health, pp. 291-302, Routledge, Abingdon, UK, 2013.

[9] C. B. Rajashekar, E. E. Carey, X. Zhao, and M. M. Oh, "Healthpromoting phytochemicals in fruits and vegetables: impact of abiotic stresses and crop production practices," Functional Plant Science and Biotechnology, vol. 3, no. 1, pp. 30-38, 2009.

[10] A. N. Panche, A. D. Diwan, and S. R. Chandra, "Flavonoids: an overview," Journal of Nutritional Science, vol. 5, 2016.

[11] G. N. Njoroge and R. W. Bussmann, "Traditional management of ear, nose and throat (ENT) diseases in Central Kenya," Journal of Ethnobiology and Ethnomedicine, vol. 2, no. 1, pp. 1-9, 2006.

[12] P. G. Kareru, G. M. Kenji, A. N. Gachanja, J. M. Keriko, and G. Mungai, "Traditional medicines among the Embu and Mbeere people of Kenya," African Journal of Traditional, Complementary and Alternative Medicines, vol. 4, no. 1, pp. 75-86, 2007.

[13] B. A. Iwalokun, B. U. Efedede, J. A. Alabi-Sofunde, T. Oduala, O. A. Magbagbeola, and A. I. Akinwande, "Hepatoprotective and antioxidant activities of Vernonia amygdalina on acetaminophen-induced hepatic damage in mice," Journal of Medicinal Food, vol. 9, no. 4, pp. 524-530, 2006.

[14] P. Alam, M. F. Alajmi, A. H. Arbab et al., "Comparative study of antioxidant activity and validated RP-HPTLC analysis of rutin in the leaves of different Acacia species grown in Saudi 
Arabia," Saudi Pharmaceutical Journal, vol. 25, no. 5, pp. 715-723, 2017.

[15] A. B. Aliyu, M. A. Ibrahim, A. M. Musa, H. Ibrahim, I. E. Abdulkadir, and A. O. Oyewale, "Evaluation of antioxidant activity of leave extract of Bauhinia rufescens Lam. (Caesalpiniaceae)," Journal of Medicinal Plants Research, vol. 3, no. 8, pp. 563-567, 2009.

[16] A. J. Harborne, Phytochemical Methods a Guide to Modern Techniques of Plant Analysis, Springer Science and Business Media, Berlin, Germany, 1998.

[17] M. Oyaizu, "Studies on products of browning reaction. Antioxidative activities of products of browning reaction prepared from glucosamine," The Japanese Journal of $\mathrm{Nu}$ trition and Dietetics, vol. 44, no. 6, pp. 307-315, 1986.

[18] W. Brand-Williams, M. E. Cuvelier, and C. Berset, "Use of a free radical method to evaluate antioxidant activity," LWT-Food Science and Technology, vol. 28, no. 1, pp. 25-30, 1995.

[19] S. M. Klein, G. Cohen, and A. I. Cederbaum, "Production of formaldehyde during metabolism of dimethyl sulfoxide by hydroxyl radical-generating systems," Biochemistry, vol. 20, no. 21, pp. 6006-6012, 1981.

[20] Q. D. Do, A. E. Angkawijaya, P. L. Tran-Nguyen et al., "Effect of extraction solvent on total phenol content, total flavonoid content, and antioxidant activity of Limnophila aromatica," Journal of Food and Drug Analysis, vol. 22, no. 3, p. 296, 2014.

[21] H.-H. Park, S. Lee, H.-Y. Son et al., "Flavonoids inhibit histamine release and expression of proinflammatory cytokines in mast cells," Archives of Pharmacal Research, vol. 31, no. 10, p. 1303, 2008.

[22] I. Fidrianny, S. Ramadhani, and R. Komar, "In vitro antioxidant capacities of three organs of bitter gourd (Momordica charantia L.) form west Java-Indonesia using DPPH and FRAP assays," International Journal of Pharmacognosy and Phytochemical Research, vol. 7, no. 5, pp. 1034-1041, 2015.

[23] M. Ferry and A.-M. Roussel, "Micronutrient status and cognitive decline in ageing," European Geriatric Medicine, vol. 2, no. 1, pp. 15-21, 2011.

[24] R. S. Sohal and W. C. Orr, "The redox stress hypothesis of aging," Free Radical Biology and Medicine, vol. 52, no. 3, pp. 539-555, 2012.

[25] D. B. Graves, "The emerging role of reactive oxygen and nitrogen species in redox biology and some implications for plasma applications to medicine and biology," Journal of Physics D: Applied Physics, vol. 45, no. 26, Article ID 263001, 2012.

[26] T. Rahman, I. Hosen, M. M. T. Islam, and H. U. Shekhar, "Oxidative stress and human health," Advances in Bioscience and Biotechnology, vol. 3, no. 7, pp. 997-1019, 2012.

[27] S. Umar, M. Asif, Sajad et al., "Anti-inflammatory and antioxidant activity of trachyspermum ammi seeds in collagen induced arthritis in rats," International Journal of Drug Development and Research, vol. 4, pp. 210-219, 2012.

[28] K. Ishino, C. Wakita, T. Shibata et al., "Lipid peroxidation generates body odor component trans-2-nonenal covalently bound to protein in vivo," Journal of Biological Chemistry, vol. 285, no. 20, pp. 15302-15313, 2010.

[29] S. R. Naik, "Antioxidants and their role in biological functions: an overview," Indian Drugs, vol. 40, pp. 501-508, 2003.

[30] A. C. Kaliora, G. V. Z. Dedoussis, and H. Schmidt, "Dietary antioxidants in preventing atherogenesis," Atherosclerosis, vol. 187, no. 1, pp. 1-17, 2006.

[31] H. Gandomi, S. Abbaszadeh, A. JebelliJavan, and A. Sharifzadeh, "Chemical constituents, antimicrobial and antioxidative effects of trachyspermum ammi essential oil," Journal of Food Processing and Preservation, vol. 38, no. 4, pp. 1690-1695, 2014.

[32] R. Salazar, M. E. Pozos, P. Cordero, J. Perez, M. C. Salinas, and N. Waksman, "Determination of the antioxidant activity of plants from northeast Mexico," Pharmaceutical Biology, vol. 46, no. 3, pp. 166-170, 2008.

[33] S. N. Saxena, D. Agarwal, R. Saxena et al., "Analysis of antioxidant properties of ajwain (Trachyspermum ammi L) seed extract," International Journal of Seed Spices, vol. 2, pp. 50-55, 2012.

[34] A. C. Akinmoladun, E. M. Obuotor, and E. O. Farombi, "Evaluation of antioxidant and free radical scavenging capacities of some Nigerian indigenous medicinal plants," Journal of Medicinal Food, vol. 13, no. 2, pp. 1-8, 2010.

[35] İ. Gülçin, "Antioxidant properties of resveratrol: a structureactivity insight," Innovative Food Science \& Emerging Technologies, vol. 11, no. 1, pp. 210-218, 2010.

[36] L. K. MacDonald-Wicks, L. G. Wood, and M. L. Garg, "Methodology for the determination of biological antioxidant capacityin vitro: a review," Journal of the Science of Food and Agriculture, vol. 86, no. 13, pp. 2046-2056, 2006.

[37] O. A. Adesanoye and E. O. Farombi, "In vitro antioxidant properties of methanolic leaf extract of Vernonia amygdalina," Nigeria Journal of Physiological Science, vol. 29, pp. 91-101, 2014.

[38] K. Sowndhararajan, J. M. Joseph, and S. Manian, “Antioxidant and free radical scavenging activities of Indian acacias: Acacia leucophloea (roxb.) Wild. Acacia ferruginea dc. Acacia dealbata link. and Acacia pennata (L.) wild," International Journal of Food Properties, vol. 16, no. 8, pp. 1717-1729, 2013.

[39] R. P. Patil, M. S. Nimbalkar, U. U. Jadhav, V. V. Dawkar, and S. P. Govindwar, "Antiaflatoxigenic and antioxidant activity of an essential oil from Ageratum conyzoides L." Journal of the Science of Food and Agriculture, vol. 90, no. 4, pp. 608-614, 2010.

[40] M. N. Vivek, S. S. HC, M. Manasa, et al., "Antimicrobial and antioxidant activity of leaf and flower extract of Caesalpinia pulcherrima, Delonix regia and Peltaphorum ferrugineum," Journal of Applied Pharmaceutical Science, vol. 3, no. 8, p. 64, 2013.

[41] I. B. Abdel-Farid, M. G. Sheded, and E. A. Mohamed, "Metabolomic profiling and antioxidant activity of some Acacia species," Saudi Journal of Biological Sciences, vol. 21, no. 5, pp. 400-408, 2014.

[42] Y. Ogasawara, T. Namai, F. Yoshino, M.-C.-i. Lee, and $\mathrm{K}$. Ishii, "Sialic acid is an essential moiety of mucin as a hydroxyl radical scavenger," FEBS Letters, vol. 581, no. 13, pp. 2473-2477, 2007.

[43] C. M. Kibiti and A. J. Afolayan, "Herbal therapy: a review of emerging pharmacological tools in the management of diabetes mellitus in Africa," Pharmacognosy Magazine, vol. 11, no. 2, p. S258, 2015.

[44] S. F. Abimbade, G. K. Oloyede, and C. C. Nwabueze, "Antioxidant and toxicity screenings of extracts obtained from Cyperus esculentus," 2014, http://repository.fuoye.edu.ng/ handle/123456789/942.

[45] G. A. Agbor, J. A. Vinson, and P. E. Donnelly, "Folin-Ciocalteu reagent for polyphenolic assay," International Journal of Food Science, Nutrition and Dietetics, vol. 3, no. 8, pp. 147-156, 2014.

[46] G. Moriasi, A. Ireri, and M. P. Ngugi, "In vitro antioxidant activities of the aqueous and methanolic stem bark extracts of 
Piliostigma thonningii (Schum.)," Journal of Evidence-Based Integrative Medicine, vol. 25, 2020.

[47] A. A. Elzaawely and S. Tawata, "Antioxidant capacity and phenolic content of Rumex dentatus L. grown in Egypt," Journal of Crop Science and Biotechnology, vol. 15, no. 1, pp. 59-64, 2012.

[48] C. M. Kibiti and A. J. Afolayan, "Preliminary phytochemical screening and biological activities ofBulbine abyssinicaUsed in the Folk medicine in the Eastern Cape province, South Africa," Evidence-Based Complementary and Alternative Medicine, vol. 2015, Article ID 617607, 12 pages, 2015.

[49] B. Tepe, M. Sokmen, H. A. Akpulat, and A. Sokmen, "Screening of the antioxidant potentials of six Salvia species from Turkey," Food Chemistry, vol. 95, no. 2, pp. 200-204, 2006.

[50] W. Zheng and S. Y. Wang, "Antioxidant activity and phenolic compounds in selected herbs," Journal of Agricultural and Food Chemistry, vol. 49, no. 11, pp. 5165-5170, 2001. 